\title{
Zurück nach Europa, aber wohin? Ins Zentrum oder an den Rand? - oder - „Wohin führt der neue Pragmatismus für die mittel- und osteuropäischen Reformländer?“
}

\author{
Rainhart Lang
}

Der Beitrag von Ralph-Elmar Lungwitz, der in vielen Teilen meine Zustimmung findet, läßt am Ende diese doch sehr wichtige Frage offen.

Die auf einer sehr interessanten, empirischen Untersuchung in insgesamt 18 Betrieben in Ostdeutschland, Polen und der Tschechischen Republik beruhenden Befunde zur Rolle des Managements bei der organisatorischen Modernisierung machen deutlich, daß der Versuch einer Orientierung am Maßstab von „modernen“ Organisationen unter Bedingungen der Transformation und Globalisierung schon deshalb zum Scheitern verurteilt war, weil die s.g. „modernen“ oder z.T. als ,postmodern“ bezeichneten Organisationskonzepte letztendlich vor allem „Redeinstrumente“ darstellen, die einer radikalen Restrukturierung im Sinne einer Anpassung an globalisierte Märkte den Weg bereiten und sie legitimieren sollen. Insofern handelt es sich weniger um eine „Entzauberung“ von Heilslehren, an denen im übrigen manche Soziologen im Glauben an das Gute, Schöne und Moderne der genannten Konzepte heftig mitgewirkt haben, als vielmehr um Managementideologien, die mit ihrer Rhetorik den Weg für eine radikale Umgestaltung bereiten sollen. Aus dieser Sichtweise heraus ist der pragmatische Umgang mit den genannten Managementkonzepten natürlich durchaus plausibel und zeugt keineswegs von der Unfähigkeit östlicher Manager, die nur die Großartigkeit von BusinessReingeneering, TQM und Empowerment nicht verstanden haben. Bedenklich stimmen vielmehr die praktizierten Lösungen, die wie Lungwitz schreibt, sich weitgehend bruchlos in die Traditionslinie eines tayloristischen Organisationsparadigmas einreihten. In Verbindung mit der in der Literatur festgestellten Rekonventionalisierung der Arbeitsorganisation ergibt sich eben die Frage, in wie weit nicht in den mittel- und osteuropäischen Reformländern vor allem jene Industrien entwickelt werden, in denen sich aufgrund traditioneller Arbeitsorganisation und vergleichsweise billigen Arbeitskräften die traditionellen Muster erhalten bzw. die „Ladenhüter“ organisatorischer Strukturierung in diesen Ländern zur Anwendung gebracht werden. Insofern geht es hier weniger um eine universelle Geltung von Organisationsparadigmen als vielmehr um die Gefahr einer ungleichen Verteilung: interessante Arbeitsinhalte, partizipative Arbeitsgestaltung, moderne, leistungsorientierte Entlohnungssysteme in den wissensorientierten Industriezweigen der 
europäischen Kernländer und monotone, taylorisierte Arbeitsinhalte mit traditionellen Hierarchien und geringen Möglichkeiten der Mitsprache in den damit auch arbeitsorganisatorisch zum Rand Europas werdenden Reformländern in Mittel- und Osteuropa. Aus dieser Sicht wird auch das Fazit von Lungwitz fraglich, zumindest wenn man es normativ versteht: das Lernen von mittel- und osteuropäischen Ländern hieße dann, die Rekonventionalisierung, die man „erfolgreich“ nach Mittel- und Osteuropa ausgelagert hat, wieder nach Mitteleuropa zurückzubringen. Ein Fazit mit dem ich mich weder von seinem Ausgangspunkt noch von seinen Endpunkten so sehr anfreunden kann. 